\title{
Productive and unproductive competition: a unified framework
}

\author{
Alice Guerra ${ }^{1}$ - Barbara Luppi ${ }^{2}$. Francesco Parisi ${ }^{3}$
}

Received: 26 January 2017/ Accepted: 18 September 2017/Published online: 30 September 2017

(C) Springer International Publishing AG 2017

\begin{abstract}
Conventional theories of competition classify contests as being either "productive", when the competitive efforts generate a surplus for society, or "unproductive", when competition generates no social surplus and merely distributes already existing resources. These two discrete categories of competition create a division of real-world situations into analytical categories that fails to recognize the entire spectrum of competitive activities. Taking the existing models of productive and unproductive competition as benchmark idealizations, this paper revisits the relationship between the privately and socially optimal levels of competition in the full range of intermediate cases, as well as in the extremum cases of destructive and super-productive competition.
\end{abstract}

Keywords Contests · Rent seeking - Unproductive competition · Productive competition $\cdot$ Patent races

JEL Classification C72 · D72

Barbara Luppi

barbara.luppi@unimore.it

Alice Guerra

agu.dbp@cbs.dk

Francesco Parisi

parisi@umn.edu

Department of Business and Politics, Copenhagen Business School, Copenhagen, Denmark

2 Department of Economics, University of Modena and Reggio Emilia, Modena, Italy

3 Department of Economics, School of Law and University of Bologna, University of Minnesota, Minneapolis, USA 


\section{Introduction}

Competition is a fundamental ingredient of efficient markets. Yet not every form of competition is productive or socially desirable. In many situations, contestants will expend costly efforts to win a prize (or a larger share of it than their competitors), even when their increasing efforts produce no additional value to society. In such situations, competition does not increase the total welfare of society, but simply generates a redistribution of resources and a dissipation of effort. Tullock (1967, 1980) introduced the concept of "unproductive competition" into the economic literature, providing a valuable tool for analyzing this previously neglected category of competition. ${ }^{1}$ In the dichotomous distinction between rent seeking and profit seeking, the incentives that the rent seekers face are those of a prisoner's dilemma (Buchanan 1980), and, once competitive expenditures are accounted for, rent-seeking becomes a negative-sum game (Tullock 1980). Following Tullock (1967, 1980), rent-seeking models have been used to explain competition in a wide variety of contexts, including political lobbying, regulatory capture, monopolies, sibling rivalry, political campaigns, all-pay auctions, trade protection, patent races, civil litigation, bureaucracy, corruption, and warfare. ${ }^{2}$

In this paper, we rely upon the traditional rent-seeking framework to revisit the various forms of competition and analyze the social and private incentives to compete, under a unified framework. Prior rent-seeking literature has mainly dealt with purely redistributive contests, building on the premise that the rent-seeking efforts do not yield any benefit to society at large. Such rent-seeking contests are juxtaposed against productive contests in which social gains are generated as a byproduct of the parties' pursuit of private gains, such as in scientific or technological research (see, among others, the introduction to Barzel 1997). In this respect, the Industrial Organization literature on patent races has extensively discussed the conditions under which the social and private values of an innovation may or may not coincide (see, among others, Denicolo 1999, and the references therein). ${ }^{3}$

Our analysis builds upon the notions of productive rivalry used by Demsetz (1976) and of rent-creation formulated by Buchanan (1980) to show and emphasize how different activities may exhibit various degrees of social productivity. Even when competition is intrinsically redistributive, there are unintended social benefit of the rent-seeking contest, which may bridge the gap between productive and

\footnotetext{
${ }^{1}$ Gordon Tullock (1967) laid the foundations for the study of "unproductive competition", which Krueger (1974) later termed "rent seeking". Bhagwati (1982) generalized the contributions of Tullock and Krueger, formulating a general theory of "directly-unproductive profit seeking". The common characteristic of these situations (and innumerably many others) is that the rents sought by the contestants are fixed - their competitive efforts do not enlarge the prize at stake. This desire to bridge the boundaries of productive and unproductive competition serves as a main motivation for this paper. On competition, socially productive rivalry and regulation, see also Demsetz $(1973,1976)$ and Crain and Ekelund (1976).

${ }^{2}$ For recent overviews of the rent-seeking literature, see Congleton et al. (2008a, b), Konrad (2009) and Congleton and Hillman (2015).

${ }^{3}$ Patent races are indeed traditionally regarded as inefficient, mainly because the winner-take-all nature of the competition leads to excessive and wasteful research expenditures (e.g., Hirshleifer 1971; Hartwick 1991). Many contributions have sought policy solutions to mitigate this problem (e.g., Ménière and Parlane 2008; Gilbert and Katz 2011).
} 
unproductive competition. ${ }^{4}$ Following Dari-Mattiacci et al. (2007), we consider a simple taxonomy of rent-seeking activities assuming that individuals carry out activities in the pursuit of a private gain, and that their activities may be more or less valuable to society as a whole. We identify a measure of social productivity of competition to distinguish five categories of competition: (i) destructive, (ii) unproductive, (iii) semi-productive, (iv) productive, and (v) super-productive competition. Recall that in the benchmark case of purely redistributive rent-seeking games, no socially beneficial by-product is generated by the parties'efforts. Conversely, in purely productive rent-seeking games, parties' efforts lead to the creation or discovery of new resources, the social value of which is equal to the parties' private evaluation of the rent (Dari-Mattiacci et al. 2007). Competitors invest costly effort to maximize their private return $V$, which may be derived from productive surplus and/or redistributive rents. $V$ is assumed to be equal for all the parties and it is always positive. Rent-seeking activities, however, may generate positive or negative externalities on third parties. Apart from the productive surplus of the competitors, the social value of the competitive activity, $T$, might include the external benefits and costs of their activities on third parties, such as the consumer surplus for a newly created market or invention, or the cost imposed by illegal activities on individuals that are not rent-seekers in the contest. ${ }^{5}$ For example, consider a patent race: $V$ represents the patentee's discounted profits during the lifetime of the patent, and $T$ the further increase (if any) in social welfare that the innovation brings about during the lifetime of the patent (this increase in social welfare is not captured by the patentee; it may be enjoyed by consumers or by other firms). ${ }^{6}$ In other words, in a patent race, $T$ might include the social benefit from the innovation which is not captured by the patentee and is therefore a positive externality of the R\&D activity. ${ }^{7}$ Let $w=\frac{T}{V}$ be the "social productivity" of the activity. Negative values of $w$ represent situations where the negative external cost of the rent seeking outweighs the possible positive factors (e.g., the case of illegal activities to import illegal drugs as in Paul and Wilhite 1994). Positive values of $w$ denote situations where the contest generates a net positive social benefit (as, for example, the consumer surplus from the creation of a new market or a new invention). We now classify the efficiency of competition in terms of $w$ :

Destructive Competition $(w<0)$. This category encompasses situations where parties compete to appropriate a benefit $V>0$. In this set of situations, the

\footnotetext{
4 Throughout the paper, depending upon the category of competition under consideration, we use the term activity in its lay meaning, encompassing both productive and unproductive undertakings. Bhagwati (1982) focused exclusively on directly unproductive, profit-seeking (DUP) activities.

5 It is worth noting that $T$ and $V$ are stationary flows: there is no dynamics in the contest apart from that generated by the innovation (Denicolo 1999).

6 In Denicolo (1999), $T$ is assumed to be strictly positive, although the author acknowledged the possibility of non-pathological examples with a null or negative $T$. Our general taxonomy includes also these latter cases.

7 In the simplest case with no externalities, $T$ is the sum of producer surplus and consumer surplus. When externalities arise, $T$ reflects also the positive or negative effects generated on society. See, among others, Congleton (1989), Paul and Wilhite (1994), Chung (1996) and Lee and Kang (1998) for examples of rent seeking with externalities.
} 
creation of a private benefit leads to a net social loss for society, $T<0$. Activities that fall in this category include criminal activities, ${ }^{8}$ political lobbying for inefficient special interest legislation, the creation of barriers to entry, and unfair competition in general. The inefficiency of this form of rent seeking is intrinsic in the parties' objectives.

Unproductive Competition $(w=0)$. This is the special case considered by Tullock (1967, 1980), and our "benchmark" for undesirable competition. This category encompasses purely distributive activities that produce a private gain for the contestants, $V>0$, but which fail to generate a corresponding benefit to society, $T=0$. Examples include political lobbying for a redistribution of rights or obligations, land disputes, civil litigation (ignoring the effects of deterrence or fairness), and other contests for the appropriation of a fixed resource (Buchanan 1983; Gupta and Swenson 2003). The special case in which $T=0$ may arise, for instance, in an already competitive market when a new firm enters the industry reducing the market share of incumbent firms. In this case, the patentee reaps the entire social benefit from the innovation during the lifetime of the patent (Denicolo 1999).

Semi-productive competition $(0<w<1)$. This category encompasses contests that, although not directly productive, generate some positive byproduct for society. Semi-productive competition arises when the social value of an activity is nonzero, but lower than the private value for the contestants, $0<T<V$. Examples include political campaigning and commercial advertising (Cowling and Mueller 1978; Littlechild 1981; Congleton 1986). ${ }^{9}$ The benefit to society is positive but lower than what is at stake for the parties.

Productive competition $(w=1)$. This category is our "benchmark" for desirable competition. It is characterized by the condition that the private and social benefits from competition are equal, $V=T>0$. Productive activities, including the discovery and exploitation of natural resources and research for the development of new goods and services can generate competition that falls in this category. In the context of patent races, the private and social values of the patent are equal in cases where, for instance, the winner of the $R \& D$ race can perfectly price discriminate (Lin 1997). ${ }^{10}$ Likewise, with perfect patent protection, productive competition occurs when the patentee reaps the entire social

\footnotetext{
${ }^{8}$ Paul and Wilhite (1994) examined the "negative externality that results from market participants use of coercion and violence in attempts to control trade in the illegal good.". They show that the social cost of rent seeking exceeds the value of resources dissipated in rent-seeking contest.

9 Advertising is a dimension of non-pricing competition through which rent seeking may occur. There is a long standing debate whether advertising is informative to consumers or wasteful, in order to measure correctly the social loss produced by rent seeking (Cowling and Mueller 1978; Littlechild 1981). See also Dixit and Norman (1978) and related work to this debate. For the purpose of our analysis, the inclusion of this example under this category is merely illustrative and has no bearing on this debate.

${ }^{10}$ Lin (1997) argued that if the winner of the patent can capture all the social value of the innovation, the $R \& D$ race in general leads to socially wasteful $R \& D$ effort due to its winner-take-all feature. In this case, licensing appears to be socially desirable if it can eliminate excessive R\&D. If instead the social value of the patent is not equal to $V$, it is not clear how licensing affects welfare: a slower innovation process is not necessarily welfare improving. In this case, the welfare effect of licensing will ultimately depend on the difference between the social and private value of the discovery.
} 
benefit from innovation during the lifetime of the patent with no residual productive value of the patent after its expiration.

Super-productive competition $(w>1)$. The social benefit exceeds the private benefit sought by the parties, $T>V>0$. We may observe this condition in cases where producers pursue a profit that does not capture the entire consumer surplus. This may indeed be the most frequently observed care, inasmuch as all competitive and imperfectly competitive markets leave a positive surplus to consumers. This may similarly include innovative patents when the innovative value of the innovation outlives the duration of the patent. In all these cases, the producers' profit, $V$, is lower than the total surplus for society, $T$.

Previous rent-seeking literature identifies various measures of "rent dissipation" by looking at the relationship between rent-seeking expenditures and the value of the sought-after rent. In this paper, we revisit the relationship between the private value of the prize, $V$, and the social value of the contest, $T$, measured as the social value of the activity at the net of the positive or negative externalities produced by the contest. Through this framework, we will show that private incentives to compete are rarely aligned with the social objective and the amount of contestants' expenditures may exceed or fall short of the socially desirable values in the full range of competitive contests. ${ }^{11}$

It is worth remarking that our paper is also related and contribute to the growing experimental contributions on contests, which generally find significant overinvestments relative to the Nash equilibrium predictions. ${ }^{12}$ Our theoretical model reveals that, among other factors, the discrepancy between private and social incentives to compete is a source of over-investment in contests. This has never been explored from an experimental perspective. For this reason, our findings can be fruitfully used as testable hypotheses for future experimental research on contests.

The analysis on how the private incentives to compete differ from the social optimum is highly relevant for policy analysis. Our results show that competition is increasingly desirable when the degree of the net social productivity of the contest increases, and that a greater use of competition-boosting policies is warranted in industries with large positive spillover effects between competitors. Interestingly, we found that when competition can be sustained in concentrated markets, the discrepancy between privately and socially optimal levels of competition is actually narrowed.

These results may be understood intuitively by considering the multiple effects of investments in effort. Consider a patent race: when a firm invests in research, it increases the probability of discovering a new technology. Obviously, society also shares in the enjoyment of this benefit. However, investments in effort also improve the probability that one firm will discover, and reduces the probability of success for competing firms. These latter effects are redistributive and accrue solely to the competing firms, with no corresponding value to society. Through this lens, we can

\footnotetext{
11 Patent-race scholars have occasionally made the point that even when competition is intrinsically good, competition may be excessive. See for example Dasgupta and Stiglitz (1980).

12 For an extensive review of the experimental literature on contests, see Dechenaux et al. (2015).
} 
see that competitive contests are characterized by the presence of reciprocal externalities, which may result in excessive competition: additional investments in research by one firm contribute to the probability of a socially valuable discovery, but creates a relative disadvantage for other firms to obtain the discovery. While discovery contributes to social welfare, the allocation of intellectual property rights among competitors has distributive effects, which affect the overall level of dissipation through competition.

\section{The model}

We consider a contest where two players compete to win a prize with value $V>0$. We assume that society has a valuation $T$ for the prize which may differ from $V$. The contestants simultaneously and independently choose their level of effort $e_{i} \geq 0, i=1,2$, to win the prize. ${ }^{13}$ Let $e^{*}\left(e^{* *}\right)$ denote the privately (socially) optimal effort level in the symmetric equilibrium.

In line with the literature on imperfectly discriminating contests-i.e., contests in which it is possible that no one wins the prize outright (e.g., Dasgupta and Nti 1998), ${ }^{14}$ we define the state space as follows: \{player 1 wins the contest; player 2 wins the contest; no player wins $\}$. These three states are mutually exclusive and their respective probabilities can be expressed with the logit form expression used by Dasgupta and Nti (1998). ${ }^{15}$

Formally, the probability that player $i=1,2$ wins the contest takes the following logit-form contest success function for imperfectly discriminating contests: ${ }^{16}$

$$
p_{i}\left(e_{i}, e_{j}\right)=\frac{h\left(e_{i}\right)}{z+h\left(e_{i}\right)+h\left(e_{j}\right)} \quad i, j=1,2 ; i \neq j,
$$

\footnotetext{
${ }^{13}$ The analysis presented here can be extended to consider an endogenous prize increasing in the level of parties' efforts. The qualitative nature of our conclusions does not change.

${ }^{14}$ Contests can be generally classified as either perfectly or imperfectly discriminating. Among others, see Hillman and Riley (1989) for a comparison of these two categories of contests. In perfectly discriminating contests, the highest effort secures the win, as, for example, in an all-pay auction (Hillman and Samet 1987; Baye et al., 1996; Krishna and Morgan 1997; Moldovanu and Sela, 2001). In imperfectly discriminating contests, a higher effort leads to a higher probability of a win, but this does not necessarily imply a win (Dixit and Norman 1978; Nitzan 1991, 1994). Most contributions on imperfectly discriminating contests adopted the logit-form contest success function (e.g., Skaperdas and Grofman 1995; Nti 1997, 1999), whereas a few papers adopted the probit form (e.g., Lazear and Rosen 1981; Dixit 1987).

${ }^{15}$ Similarly, our analytical framework is a special case of the 'success function with possibility of a draw' defined in Blavatskyy (2010). Blavatskyy (2010) defined a draw as the contest outcome without either side winning, when two or more contestants obtain equal rights for the prize and they share the price. In this respect, we consider the case in which the contest outcome is restricted (i.e., either one of the contestants wins the contest unilaterally or all contestants end up in a draw; Blavatskyy 2010, Section 3.2, p. 272), and, in the case of a draw, the prize is not shared among contestants (for example, it is retained by the contest designer as in Dasgupta and Nti 1998).

16 The specific functional form adopted here follows Dasgupta and Nti (1998, Equation 1, p. 590) with the difference that we consider imperfectly discriminating contests $(z>0)$.
} 
where $z>0$ is a constant positive likelihood that nobody will win the contest and $h\left(e_{i}\right), i=1,2$, is a twice differentiable, increasing and concave function, $h^{\prime}\left(e_{i}\right)>0, h^{\prime \prime}\left(e_{i}\right)<0$, with $h(0)=0$. The function $h\left(e_{i}\right), i=1,2$ is chosen to ensure that the first-order conditions of the private and social optimization problems always have a solution. ${ }^{17}$ The constant $z$ can be interpreted for example as the overall difficulty of the research in a patent race contest or a situation in which the contest designer may retain the prize (Dasgupta and Nti 1998). As $z \rightarrow 0$, each player tends to have zero probability of winning the contest if none of them invest in effort. However, if players exert some effort, the prize tends to be awarded to one of them quite for sure. On the opposite, as $z \rightarrow+\infty$ each player tends to have zero probability of winning the contest even if all of them invest in effort. In this type of contests, the likelihood that the prize will not be awarded to any of the contestants is very high. The assumptions on $h\left(e_{i}\right), i=1,2$, ensure that each player's chance of winning the contest increases with his expenditure at a decreasing rate, and decreases with the other contestant's expenditures at an increasing rate.

The logit form of contests as described in Eq. (1) and the function $h($.$) with the$ properties mentioned above are ubiquitous in the literature and allow us to work with concave contest success functions. This assures the existence of a unique (private and social) equilibrium expenditure, as we prove for each proposition in the Appendix. ${ }^{18}$

The expected payoff of player $i=1,2$ is the expected private value of the contest, at the net of expenditures: ${ }^{19}$

$$
R_{i}=p_{i}\left(e_{i}, e_{j}\right) V-e_{i}=\frac{h\left(e_{i}\right) V}{z+h\left(e_{i}\right)+h\left(e_{j}\right)}-e_{i} \quad i, j=1,2 ; i \neq j
$$

The expected social value of the contest is given by the probability that one of the two firms wins, ${ }^{20}$ at the net of both players' expenditures:

$$
\left(p_{1}\left(e_{1}, e_{2}\right)+p_{2}\left(e_{1}, e_{2}\right)\right) T-e_{1}-e_{2}=\frac{\left(h\left(e_{1}\right)+h\left(e_{2}\right)\right) T}{z+h\left(e_{1}\right)+h\left(e_{2}\right)}-e_{1}-e_{2} .
$$

Society benefits are obtained if at least one of the two firms make the discovery, regardless of which of the two firms is the first to discover. However, from the contestant's perspective, a private benefit accrues only if he is the first to discover. This creates a discrepancy between the private incentives to compete and the social objective. In the following we study the conditions under which private and social optima diverge on the basis of $w=\frac{T}{V}$, interpreted as the social productivity of the activity.

\footnotetext{
17 This remark clearly holds also in Sect. 3, where each agent has a linear production function for effective investment.

18 The proof of the existence of a pure strategy symmetric Nash equilibrium in this type of contest follow Dasgupta and Nti (1998). See also Blavatskyy (2010).

19 As in Dasgupta and Nti (1998) and Blavatskyy (2010), we implicitly assume throughout the analysis that the losing prize is zero. For an analysis of contests with a positive losing prize, see Baye et al. (2012). 20 The probability that "one of the two firms discovers" is the sum of the probabilities of "firm 1 discovers first" and "firm 2 discovers first" by mutual exclusivity.
} 
Proposition 1 (Private incentives to compete) Private incentives to compete exceed (equal) the socially optimal levels for all values of $w<1+h\left(e^{*}\right) / z$ $\left(w=1+h\left(e^{*}\right) / z\right)$. Private incentives to compete fall below the socially optimal levels when $w>1+h\left(e^{*}\right) / z$.

Corollary 2 (Social productivity and optimal competition) In the benchmark case considered in Proposition 1, competitive efforts are excessively high in all cases of destructive, unproductive, semi-productive and productive competition and can also be excessive for some cases of super-productive competition.

\section{Proof See Appendix.}

Proposition 1 and Corollary 2 compare the privately and socially optimal levels of effort and identify the conditions under which contestants compete more (or less) than would be desirable from a social welfare perspective. Proposition 1 tells us the range of excessive competition is much more extensive than one might think. It is interesting to observe here that in the conventional dichotomy (Buchanan 1980), all rent seeking is by definition "excessive" inasmuch as it is unproductive. However, once the unintended external effects of the contest are taken into account, a more nuanced evaluation becomes necessary. Interestingly, our analysis reveals that the conditions for suboptimal and excessive competition do not correspond to the threshold values of $w$ used in our taxonomy in Section 2. This can be explained by considering that the private benefit of a marginal increase in effort is greater than the social benefit, whereas the private and social marginal costs are both equal to 1 . Firms will thus over-invest in effort when $w \leq 1$. This implies that competitive contests lead to excessive competition in all cases of destructive, unproductive, semi-productive and productive competition. Excessive levels of competition can also be observed in the initial range of super-productive competition, when $1<w<\underline{w}$. Suboptimal levels of competition may, instead, be observed in the upper range of super-productive competition, when $w>\underline{w}$. In this case, the social value of production $T$ is sufficiently larger than the private value of production $V$, and the parties' private incentives do not account for the full social value of the discovery.

In cases of productive competition where firms capture the full social benefit of their production, excessive competition is observed. For example, by considering patent races, this situation can ideally happen when firms can perfectly price discriminate and the patent protection covers the entire productive life-span of the discovery. The problem is luckily mitigated and we may approach optimal levels of competition when firms are unable to capture the entire consumer surplus and/or when the productive value of the discovery outlives the duration of the patent protection.

Analytically, the threshold $\underline{w}$ equals $1+h\left(e^{*}\right) / z$. To understand this threshold, consider that in the absence of competition $(n=1)$, the firm appropriates the full value of its research. Private and social optima will thus converge when $T=V$ (i.e., $\underline{w}=1)$. Excessive (suboptimal) efforts will be observed when $T<V(T>V)$. However, imperfect appropriation of the prize occurs when two or more contestants compete for the prize. The threshold $\underline{w}$ therefore increases above 1 , by the ratio $h\left(e^{*}\right) / z$ which measures the relative difficulty of the contest, i.e., the probability that 
the opponent wins the prize relative to the overall probability that neither contestant wins the prize.

As the contest becomes riskier (that is, $z \rightarrow+\infty$ ), the threshold tends to 1 independently from the effort exerted by the parties. When contestants do not fully appropriate the value of their research, a convergence of private and social optima occurs when $T>V$. On the opposite, in contests with at least one winner (that is, when $z \rightarrow 0$ ), the threshold increases above 1 .

The analysis above provides a lens through which we can analyze how the private incentives to compete differ from the social optimum. A rigorous understanding of the social desirability of competition is highly relevant for policy analysis, inasmuch as it allows us to identify the range of cases where competition levels fall short or exceed the socially optimal levels. Competition-boosting policies are warranted when private incentives to compete fall short of the social optimum, while constraints on competition become desirable to tame excessive levels of competition.

\section{Some extensions}

In Sect. 2 we showed that for a broad range of contexts, competition that is intrinsically productive can nevertheless lead to excessive dissipation and become socially undesirable. In the following, we shall recast these results by considering some extensions that may illuminate the problem of dissipation in real life competitive situations.

\subsection{Contests with positive spillover effects}

Spillover effects and positive externalities are pervasive in industries characterized by research and innovation. For example, positive spillover effects are often found in research races, where the discoveries of a firm benefit the parallel research efforts of competitors and create spillover effects throughout the industry (e.g., Hartwick 1991; Fung 2002; Baye et al. 2012; Chowdhury and Sheremeta 2011a, b, 2015). ${ }^{21}$ Consider the case where each party's competitive efforts produce positive effects on the other contestants' probability of winning the prize. Each agent has a linear production function for effective investment, and the marginal rate of technical substitution among the private effort and the spillover effect does not vary across the

\footnotetext{
${ }^{21}$ In the R\&D literature, the term "spillover effect" is generally used when knowledge of the R\&D results leaks to other firms (Arrow 1962). Baye and Hoppe (2003) argued that innovation tournaments exhibit not only negative externalities due to the well-known negative business-stealing effect, but also positive externalities among players' R\&D efforts due to a "leap-frogging effect" on the value of the prize. Baye et al. (2012) and Chowdhury and Sheremeta (2011a, b, 2015) examined contests in which winner and loser prizes may be asymmetrically influenced by rival effort. See also Dechenaux and Mancini (2008) analyzing a generalized contest payoff function in all-pay auctions.
} 
contestants. The probability that player $i$ wins the contest takes the following logitform contest success function: ${ }^{22}$

$$
p_{i, s}=\frac{e_{i, s}+\theta e_{j, s}}{z+e_{i, s}+e_{j, s}+\theta\left(e_{i, s}+e_{j, s}\right)} \quad i, j=1,2 ; i \neq j,
$$

with $\theta \in(0,1]$ and where $\theta e_{j}, j \in\{1,2\}, i \neq j$ represents the positive spillover of the effort of player $j$ on the probability of success of player $i$. Player $i$ 's probability of winning the contest is increasing in his expenditure at a decreasing rate, and decreases with the other contestant's expenditures at an increasing rate. This implies $e_{i, s}\left(1-\theta^{2}\right)-\theta z>0, \forall i \in\{1,2\} .^{23}$ The expected payoff of player $i, R_{i, s}$, and the expected social value with positive spillover effects are given by (2) and (3) substituting (4).

Proposition 3 (Private incentives to compete with positive spillover effects) Spillover effects mitigate the problem of excessive competition. Private incentives to compete exceed (equal) the socially optimal levels for all values of $w<\underline{w}_{s}\left(w=\underline{w}_{s}\right)$, where $\underline{w}_{s}=1+\frac{e_{s}^{*}\left(1-\theta^{2}\right)-\theta z}{z(1+\theta)}$. With positive spillovers, the threshold value is always $\underline{w}_{s}<\underline{w}$. This implies that the range of cases characterized by excessive competition is narrowed when positive spillover effects are present.

Corollary 4 (Social productivity and optimal competition with positive spillover effects) In the presence of positive spillover effects, the threshold $\underline{w}_{s}$ shifts to the left and suboptimal levels of competition may be observed in the range of productive or semi-productive competition.

\section{Proof See Appendix.}

The assessment of the social desirability of competition when positive externalities and spillover effects are present changes substantially the results derived in Sect. 3.1. Positive externalities and spillover effects mitigate the problem of excessive competition, lowering the threshold which discriminate between excessive and sub-optimal private efforts.

Modern legal systems and norms in the scientific community tend to allocate rights and academic recognitions on a first-in-time basis when activities are superproductive. Consider for example the competitive allocation of rights for patentable innovations and scientific discoveries. The super-productive nature of those activities is due to the fact that the private value of a patentable innovation is

\footnotetext{
22 The specific anonymous logit CSF here adopted follows Münster (2009) and Rai and Sarin (2009), where the success functions are designed to capture positive spillover effects and multidimensional efforts.

23 Our analysis is consistent with $\theta$ ranging in the interval $(0,1]$ and $z>\left(1-\theta^{2}\right) / \theta$. This allows negative spillovers to have more impact on each party's winning probability than positive spillovers. This is intuitive: if more than $100 \%$ of each player's effort can be exploited by the competitor(s), players would find the contest not appealing and they are very unlikely to enter in competition. Relaxing these conventional assumptions has the potential to generate convexity issues that may undermine the existence of a unique Nash equilibrium. The coexistence of weak and strong positive spillover effects in competition may be a fruitful avenue for future theoretical and experimental research.
} 
linked to the expected value of the producer's profit during the protected period, and fails to capture the consumer surplus produced after the expiration of the patent. Similarly, scientific research yields knowledge and informational benefits to society at large, that are not appropriated by the discoverer. In both cases, the competitors' stakes are smaller than the full social value of their efforts, hence falling within the category of super-productive competition in our taxonomy. Proposition 3 and Corollary 4 interestingly show that for those situations, the competitive incentives created by competitive allocation rules may thus be closely aligned with the social objective. The presence of positive spillovers reduces the range of cases of excessive competition identified in Proposition 1 and Corollary 2. For example, consider $R \& D$ competitions. If the $R \& D$ investments done by one firm can be exploited by another firm without purchasing any right to do so, then the private $\mathrm{R} \& \mathrm{D}$ investment incentives tend to be too low, relative to the social incentive, because each firm's R\&D investments may strengthen competitors.

Dissipation will therefore be less severe in industries characterized by positive spillover effects. However, positive spillovers increase the number of situations with insufficient levels of competition. We may observe suboptimal levels of competition not only for super-productive competition, but also for productive and semi-productive competition, with the critical threshold $\underline{w}_{s}$ taking any value above zero. Competition-boosting policies may thus be (relatively more) warranted in industries with larger positive spillover effects.

\subsection{Contests with positive spillover effects and multiple contestants}

A natural extension of the foregoing model involves competitive contests among multiple firms. When multiple firms participate in a competitive contest, unavoidably each individual firm has a smaller chance of winning. This dilutes the expected return from each contestant's investment. We exemplify the analysis considering the case of three firms. In order to establish the socially optimal level of competition, we follow Nti (1997), Münster (2009), Rai and Sarin (2009), and we define the probability that player $i \in\{1,2,3\}$ wins the contest as follows:

$$
p_{i, s m}=\frac{e_{i, s m}+\theta\left(e_{j, s m}+e_{k, s m}\right)}{z+(1+2 \theta)\left(e_{i, s m}+e_{j, s m}+e_{k, s m}\right)} \quad i, j, k=1,2,3 ; i \neq j \neq k .
$$

As in the case with two contestants, each player's chance of winning increases with his expenditure at a decreasing rate. The expected payoff of player $i, R_{i, s m}$, and the expected social value, with $i \in\{1,2,3\}$, are given by (2) and (3) substituting (5).

Proposition 5 (Social productivity and optimal competition with three contestants) In the absence of spillovers, an increase in the number of competing firms reduces the efforts of each individual firm, $e_{m}^{*}<e^{*}$, while increasing the aggregate efforts of all contestants, $3 e_{m}^{*}>2 e^{*}$. An increase in the number of contestants widens the range of cases characterized by excessive competition. Specifically, competitive efforts remain above the socially optimal values for $w<\underline{w}_{m}$, where 
$\underline{w}_{m}=1+\frac{2 e_{m}^{*}}{z}$. The threshold increases by increasing the number of contestants, i.e., $\underline{w}_{m}>\underline{w}$.

Corollary 6 (Social productivity and optimal competition with positive spillover and three contestants) In the presence of spillovers, an increase in the number of firms has an indeterminate effect on the threshold $\underline{w}_{s m}$, where $\underline{w}_{s m}=1+\frac{2\left(e_{s m}^{*}(1-\theta)(1+2 \theta)-\theta z\right)}{z(1+2 \theta)}$. The threshold $\underline{w}_{s m}$ increases when the competition effect dominates the spillover effect, i.e., $\underline{w}_{s m}>\underline{w}_{s}$.

\section{Proof See Appendix.}

An increase in the number of contestants exacerbate the over-dissipation problem identified in Proposition 1 and Corollary 2, when no spillover effects are present. Specifically, Proposition 5 reveals that the presence of multiple competitors (i) reduces individual efforts, (ii) increases aggregate efforts, and (iii) increases the threshold of socially optimal competition. The first two results are consistent with the standard results in the rent-seeking literature (Tullock 1980; Nti 1997). The third result is novel: not only do aggregate efforts increase, but the range of cases where socially undesirable dissipation materializes also expands to include what may have been efficient (or closer to efficient) competition with fewer competitors. It is interesting to observe the apparent tension between the first and the third points. Despite the fact that contestants expend less effort when $n$ grows larger, the misalignment between private and social optima increases and each contestant's effort departs further from the socially optimal levels. Given that the range of situations characterized by excessive competition increases in $n$, the problem of excessive dissipation through competition in fragmented markets may be more severe and may be observed in a wider range of values of social productivity. This result seems to run against the conventional wisdom in competition policy. Market concentration-problematic as it may be for sustaining actual competition-may actually mitigate the problem of excessive dissipation. When competition can be sustained in concentrated markets, the gap between privately and socially optimal levels of competition will actually be narrower.

Finally, in the presence of spillover effects, an increase in the number of contestants has a double-edged effect, with indeterminate effects on the social desirability of competition. With more contestants, dissipation increases, but so do the aggregate spillover effects. For example, consider R\&D competitions. As the number of contestants increases, aggregate effort increases as well. At the same time, however, since each firm's R\&D investment can be exploited by an increased number of competitors, aggregate effort decreases. Thus, the overall effect is ambiguous.

\section{Concluding remarks}

The received view in competition scholarship is that the desirability of competition hinges upon the social productivity of the underlying activity: productive competition is desirable and should be encouraged, and unproductive competition 
is undesirable and should be discouraged. By focusing most of the attention on these idealized cases, competition scholars have little explored the gradations of social productivity that characterize most real-world competitive contests. In this paper, we provide a unified analytical framework bridging the gap between the models of productive and unproductive contests. By reformulating the standard rent-seeking model to represent both unproductive and productive competition, we identified several additional categories: destructive, semi-productive and super-productive competition. In this setting, we show that the alignment of privately and socially optimal levels of competition hinges upon a variety of factors and formulated several refinements to the conventional wisdom on the social desirability of competition.

There are important lessons that emerge from our taxonomy. Our analysis reveals that incentive misalignment can lead to excessive dissipation through competition in most competitive situations, spanning across all cases of destructive, unproductive, quasi-productive, productive, and even super-productive competition. Competition is increasingly desirable when the degree of the net social productivity of the contest increases. The results are extended to consider the cases of positive spillover effects on the other contestant's probability and multiple contestants. Due to spillover effects, suboptimal levels of competition can be observed not only for superproductive competition, but also for productive and semi-productive competition. A greater use of competition-boosting policies may thus be warranted in industries with larger positive spillover effects. When multiple contestants are involved, the misalignment between private and social optima increases and this raises the threshold that separates excessive from suboptimal private efforts. Despite the fact that contestants expend less effort when the number of contestant grows larger, the level of competition may exceed the social optimum. Finally, our results show that in concentrated markets, when collusion can be avoided, the cases of suboptimal competition are actually fewer than previously believed. Future research could fruitfully exploit our analytical framework to study different categories of competition and alternative intellectual property and reward systems in competitive contests.

\section{Appendix}

Proof of Proposition 1 and of Corollary 2 The privately optimal investments in effort $e_{i}^{*}, i \in\{1,2\}$ are given by:

$$
\frac{\left(z+h\left(e_{j}\right)\right) h^{\prime}\left(e_{i}^{*}\right) V}{\left(z+h\left(e_{i}^{*}\right)+h\left(e_{j}\right)\right)^{2}}=1 \quad i, j=1,2 ; i \neq j
$$

The second order sufficiency conditions for $e_{i}^{*}$ to be an interior Nash equilibrium, i.e., 


$$
\frac{\left(z+h\left(e_{j}\right)\right) h^{\prime \prime}\left(e_{i}^{*}\right) V}{\left(z+h\left(e_{i}^{*}\right)+h\left(e_{j}\right)\right)^{2}}-\frac{2\left(z+h\left(e_{j}\right)\right)\left(h^{\prime}\left(e_{i}^{*}\right)\right)^{2} V}{\left(z+h\left(e_{i}^{*}\right)+h\left(e_{j}\right)\right)^{3}}
$$

for $i, j=1,2 ; i \neq j$, are satisfied since $h^{\prime}\left(e_{i}\right)>0$ and $h^{\prime \prime}\left(e_{i}\right)<0, \forall i$. In equilibrium, $e_{1}^{*}=e_{2}^{*}=e^{*}$, where $e^{*}$ is given by:

$$
\frac{\left(z+h\left(e^{*}\right)\right) h^{\prime}\left(e^{*}\right) V}{\left(z+2 h\left(e^{*}\right)\right)^{2}}=1
$$

To ensure that $e^{*}$ is an equilibrium effort per player with payoff function $R_{i}$, we have to show that $e^{*}$ is in fact a global optimum for $R_{i}$ given the other player is choosing $e^{*}$. But this follows straightforwardly from the concavity of $R_{i}$ in $e_{i}$, as shown in (7). Thus, the sufficiency condition for $e^{*}$ to be an interior Nash equilibrium is clearly satisfied and this implies a unique pure strategy equilibrium. The socially optimal investments in effort $e_{i}^{* *}, i \in\{1,2\}$, are computed as the solutions of the following FOCs:

$$
\frac{z h^{\prime}\left(e_{i}^{* *}\right) T}{\left(z+h\left(e_{i}^{* *}\right)+h\left(e_{j}\right)\right)^{2}}=1 \quad i, j=1,2 ; i \neq j
$$

The second order sufficiency conditions for $e_{i}^{* *}$ to be an interior Nash equilibrium, i.e.,

$$
\frac{z h^{\prime \prime}\left(e_{i}^{* *}\right) T}{\left(z+h\left(e_{i}^{* *}\right)+h\left(e_{j}\right)\right)^{2}}-\frac{2 z\left(h^{\prime}\left(e_{i}^{* *}\right)\right)^{2} T}{\left(z+h\left(e_{i}^{* *}\right)+h\left(e_{j}\right)\right)^{3}}
$$

for $i, j=1,2 ; i \neq j$, are satisfied since $h^{\prime}\left(e_{i}\right)>0$ and $h^{\prime \prime}\left(e_{i}\right)<0, \forall i$. In equilibrium, $e_{1}^{* *}=e_{2}^{* *}=e^{* *}$, where $e^{* *}$ is given by:

$$
\frac{z h^{\prime}\left(e^{* *}\right) T}{\left(z+2 h\left(e^{* *}\right)\right)^{2}}=1
$$

The second order sufficiency condition for $e^{* *}$ to be an interior Nash equilibrium is clearly satisfied. The first order conditions (8) and (11) lead to

$$
\left(\frac{z+2 h\left(e^{*}\right)}{z+2 h\left(e^{* *}\right)}\right)^{2} \frac{h^{\prime}\left(e^{* *}\right)}{h^{\prime}\left(e^{*}\right)}=\left(1+\frac{h\left(e^{*}\right)}{z}\right) \frac{V}{T}
$$

The LHS in (12) is larger than 1 if and only if $e^{*} \geq e^{* *}$. Conversely, the RHS in (12) is always larger than 1 when $V \geq T$. When $V<T$, the RHS in (12) is larger than 1 if and only if $w \leq \underline{w}$, where:

$$
\underline{w}=1+\frac{h\left(e^{*}\right)}{z}
$$

Thus, $w \leq \underline{w}$ is a necessary and sufficient condition for $e^{*} \geq e^{* *}$ when $V<T$. 
Proof of Proposition 3 and of Corollary 4 Player $i$ 's probability of winning the contest is increasing in his expenditure at a decreasing rate:

$$
\begin{aligned}
\frac{\partial p_{i, s}}{\partial e_{i}} & =\frac{z+e_{j, s}\left(1-\theta^{2}\right)}{\left(z+e_{i, s}+e_{j, s}+\theta\left(e_{i, s}+e_{j, s}\right)\right)^{2}}>0 \\
\frac{\partial^{2} p_{i, s}}{\partial e_{i}^{2}} & =-\frac{2(1+\theta)\left(z+e\left(1-\theta^{2}\right)\right)}{\left.z+e_{i, s}+e_{j, s}+\theta\left(e_{i, s}+e_{j, s}\right)\right)^{3}}<0
\end{aligned}
$$

The marginal impact of an increase of one player's effort on the other player's probability of winning the contest is defined as:

$$
\begin{gathered}
\frac{\partial p_{i, s}}{\partial e_{j}}=-\frac{e_{i, s}\left(1-\theta^{2}\right)-\theta z}{\left(z+e_{i, s}+e_{j, s}+\theta\left(e_{i, s}+e_{j, s}\right)\right)^{2}} \\
\frac{\partial^{2} p_{i, s}}{\partial e_{j}^{2}}=\frac{2(1+\theta)\left(e_{i, s}\left(1-\theta^{2}\right)-\theta z\right)}{\left(z+e_{i, s}+e_{j, s}+\theta\left(e_{i, s}+e_{j, s}\right)\right)^{3}}
\end{gathered}
$$

Player $i$ 's probability of winning the contest is decreasing in the other player's expenditure at an increasing rate. This implies $e_{i, s}\left(1-\theta^{2}\right)-\theta z>0$.

The privately optimal investments in effort $e_{i, s}^{*}, i \in\{1,2\}$, are given by:

$$
\frac{\left(z+e_{j, s}\left(1-\theta^{2}\right)\right) V}{\left(z+\left(e_{i, s}^{*}+e_{j, s}\right)(1+\theta)\right)^{2}}=1 \quad i, j=1,2 ; i \neq j
$$

with $\theta \in(0,1]$. The second order sufficiency conditions for $e_{i, s}^{*}$ to be an interior Nash equilibrium, i.e.,

$$
-\frac{2(1+\theta)\left(z+e_{j, s}\left(1-\theta^{2}\right)\right) V}{\left(z+\left(e_{i, s}^{*}+e_{j, s}\right)(1+\theta)\right)^{3}}
$$

are always satisfied $\forall i, j=1,2, i \neq j$. In equilibrium, $e_{1, s}^{*}=e_{2, s}^{*}=e_{s}^{*}$, where $e_{s}^{*}$ is given by:

$$
\frac{\left(z+e_{s}^{*}\left(1-\theta^{2}\right)\right) V}{\left(z+2 e_{s}^{*}(1+\theta)\right)^{2}}=1
$$

The second order sufficiency condition for $e_{s}^{*}$ to be an interior Nash equilibrium is clearly satisfied. By deriving $e_{s}^{*}$ from (20) and $e^{*}$ from the linear specification of (8), it follows that $e_{s}^{*}<e^{*}$ for $\theta \in(0,1]$. The socially optimal investments in effort $e_{i, s}^{* *}, i \in\{1,2\}$, are computed as the solutions of the following FOCs: 


$$
\frac{z(1+\theta) T}{\left.\left(z+\left(e_{i, s}^{* *}+e_{j, s}\right)(1+\theta)\right)\right)^{2}}=1 \quad i, j=1,2 ; i \neq j
$$

The second order sufficiency conditions for $e_{i, s}^{* *}$ to be an interior Nash equilibrium, i.e.,

$$
-\frac{2 z(1+\theta)^{2} T}{\left.\left(z+\left(e_{i, s}^{* *}+e_{j, s}\right)(1+\theta)\right)\right)^{3}}
$$

are always satisfied for $i, j=1,2, i \neq j$. In equilibrium, $e_{1, s}^{* *}=e_{2, s}^{* *}=e_{s}^{* *}$, where $e_{s}^{* *}$ is given by:

$$
\frac{z(1+\theta) T}{\left(z+2 e_{s}^{* *}(1+\theta)\right)^{2}}=1
$$

The second order sufficiency condition for $e_{s}^{*}$ to be an interior Nash equilibrium is clearly satisfied.

The first order conditions (20) and (23) lead to

$$
\left(\frac{z+2 e_{s}^{*}(1+\theta)}{z+2 e_{s}^{* *}(1+\theta)}\right)^{2}=\left(1+\frac{e_{s}^{*}\left(1-\theta^{2}\right)-\theta z}{z(1+\theta)}\right) \frac{V}{T}
$$

The LHS in (24) is larger than 1 if and only if $e_{s}^{*} \geq e_{s}^{* *}$. Conversely, the RHS in (24) is larger than 1 if and only if $w \leq \underline{w}_{s}$, where:

$$
\underline{w}_{s}=1+\frac{e_{s}^{*}\left(1-\theta^{2}\right)-\theta z}{z(1+\theta)}
$$

Thus, $w \leq \underline{w}_{s}$ is a necessary and sufficient condition for $e_{s}^{*} \geq e_{s}^{* *}$. Since $e_{s}^{*}<e^{*}$, when $e_{s}^{*}\left(1-\theta^{2}\right)-\theta z>0, \underline{w}>\underline{w}_{s}>1$. When $e_{s}^{*}\left(1-\theta^{2}\right)-\theta z=0, \underline{w}>\underline{w}_{s}=1$; when $e_{s}^{*}\left(1-\theta^{2}\right)-\theta z<0,0<\underline{w}_{s}<1<\underline{w}$.

Proof of Proposition 5 and Corollary 6 Player $i$ 's probability of winning the contest is increasing in his expenditure at a decreasing rate:

$$
\begin{gathered}
\frac{\partial p_{i, s m}}{\partial e_{i, s m}}=\frac{z+\left(e_{j, s m}+e_{k, s m}\right)(1-\theta)(1+2 \theta)}{\left(z+\left(e_{i, s m}+e_{j, s m}+e_{k, s m}\right)(1+2 \theta)\right)^{2}}>0 \\
\frac{\partial^{2} p_{i, s m}}{\partial e_{i, s m}^{2}}=-\frac{6 z+2\left(e_{j, s m}+e_{k, s m}\right)(1-\theta)(1+2 \theta)^{2}}{\left(z+\left(e_{i, s m}+e_{j, s m}+e_{k, s m}\right)(1+2 \theta)\right)^{3}}<0
\end{gathered}
$$

with $\theta \in(0,1]$. The marginal impact of an increase of one player's effort on the other players probability of winning the contest is defined as follows: 


$$
\begin{gathered}
\frac{\partial p_{i, s m}}{\partial e_{j, s m}}=-\frac{e_{i, s m}(1-\theta)(1+2 \theta)-\theta z}{\left(z+\left(e_{i, s m}+e_{j, s m}+e_{k, s m}\right)(1+2 \theta)\right)^{2}} \\
\frac{\partial^{2} p_{i, s m}}{\partial e_{j, s m}^{2}}=\frac{2(1+2 \theta)\left(e_{i, s m}(1-\theta)(1+2 \theta)-\theta z\right)}{\left(z+\left(e_{i, s m}+e_{j, s m}+e_{k, s m}\right)(1+2 \theta)\right)^{3}}
\end{gathered}
$$

with $i, j, k=1,2,3, i \neq j \neq k$. Player $i$ 's probability of winning the contest is decreasing in the other player's expenditures at an increasing rate. This implies $e_{i, s m}(1-\theta)(1+2 \theta)-\theta z>0$.

The privately optimal investments in effort $e_{i, s m}^{*}, i \in\{1,2,3\}$ are given by:

$$
\frac{\left(z+\left(e_{j, s m}+e_{k, s m}\right)(1-\theta)(1+2 \theta)\right) V}{\left(z+\left(e_{i, s m}^{*}+e_{j, s m}+e_{k, s m}\right)(1+2 \theta)\right)^{2}}=1 \quad i, j, k=1,2,3 ; i \neq j \neq k
$$

The second order sufficiency conditions for $e_{i, s m}^{*}$ to be an interior Nash equilibrium, i.e.,

$$
-\frac{\left(6 z+2\left(e_{j, s m}+e_{k, s m}\right)(1-\theta)(1+2 \theta)^{2}\right) V}{\left(z+\left(e_{i, s m}^{*}+e_{j, s m}+e_{k, s m}\right)(1+2 \theta)\right)^{3}}
$$

are always satisfied $\forall i, j, k \in\{1,2,3\}$. In equilibrium, $e_{1, s m}^{*}=e_{2, s m}^{*}=e_{3, s m}^{*}=e_{s m}^{*}$, where $e_{s m}^{*}$ is given by:

$$
\frac{\left(z+2 e_{s m}^{*}(1-\theta)(1+2 \theta)\right) V}{\left(z+3 e_{s m}^{*}(1+2 \theta)\right)^{2}}=1
$$

The second order sufficiency condition for $e_{s m}^{*}$ to be an interior Nash equilibrium is clearly satisfied. By deriving $e_{s}^{*}$ from (20) and $e_{s m}^{*}$ from (32), it can be shown that $e_{s}^{*}>e_{s m}^{*}$, for all $V, z>0$ such that $e_{s}^{*}, e_{s m}^{*}>0$. In the absence of spillover (i.e., $\theta=0)$, (32) becomes:

$$
\frac{\left(z+2 e_{m}^{*}\right) V}{\left(z+3 e_{m}^{*}\right)^{2}}=1
$$

By deriving $e^{*}$ from the linear specification of (8) and $e_{m}^{*}$ from (33), it follows that $e_{m}^{*}<e^{*}$, and that $3 e_{m}^{*}>2 e^{*}, \forall V, z>0$. The socially optimal investments in effort $e_{i, s m}^{* *}, i \in\{1,2,3\}$, are computed as the solutions of the following FOCs:

$$
\frac{z(1+2 \theta) T}{\left(z+\left(e_{i, s m}^{* *}+e_{j, s m}+e_{k, s m}\right)(1+2 \theta)\right)^{2}}=1 \quad i, j, k=1,2,3 ; i \neq j \neq k
$$

The second order sufficiency conditions for $e_{i, s m}^{* *}$ to be an interior Nash equilibrium, i.e., 


$$
-\frac{2 z(1+2 \theta)^{2} T}{\left(z+\left(e_{i, s m}^{* *}+e_{j, s m}+e_{k, s m}\right)(1+2 \theta)\right)^{3}}
$$

are always satisfied. In equilibrium, $e_{1, s m}^{* *}=e_{2, s m}^{* *}=e_{3, s m}^{* *}=e_{s m}^{* *}$, where $e_{s m}^{* *}$ is given by:

$$
\frac{z(1+2 \theta) T}{\left(z+3 e_{s m}^{* *}(1+2 \theta)\right)^{2}}=1
$$

The second order sufficiency condition for $e_{s m}^{* *}$ to be an interior Nash equilibrium is clearly satisfied. In the absence of spillover (i.e., $\theta=0$ ), (36) becomes:

$$
\frac{z T}{\left(z+3 e_{m}^{* *}\right)^{2}}=1
$$

The first order conditions (32) and (36) lead to

$$
\left(\frac{z+3 e_{s m}^{*}(1+2 \theta)}{z+3 e_{s m}^{* *}(1+2 \theta)}\right)^{2}=\left(1+\frac{2\left(e_{s m}^{*}(1-\theta)(1+2 \theta)-\theta z\right)}{z(1+2 \theta)}\right) \frac{V}{T}
$$

The LHS in (38) is larger than 1 if and only if $e_{s m}^{*} \geq e_{s m}^{* *}$. Conversely, the RHS in (38) is always equal or larger than 1 if an only if $w \leq \underline{w}_{s m}$, where:

$$
\underline{w}_{s m}=1+\frac{2\left(e_{s m}^{*}(1-\theta)(1+2 \theta)-\theta z\right)}{z(1+2 \theta)}
$$

Thus, $w \leq \underline{w}_{s m}$ is a necessary and sufficient condition for $e_{s m}^{*} \geq e_{s m}^{* *}$. Given $e_{s}^{*}>e_{s m}^{*}$, by comparing (25) and (39) it follows that $\underline{w}_{s}<\underline{w}_{s m}$ when $2 e_{s m}^{*}>e_{s}^{*}$. In the absence of spillover (i.e., $\theta=0)$, (38) becomes:

$$
\frac{\left(z+3 e_{m}^{*}\right)^{2}}{\left(z+3 e_{m}^{* *}\right)^{2}}=\left(1+\frac{2 e_{m}^{*}}{z}\right) \frac{V}{T}
$$

The LHS in (40) is larger than (equal to) 1 if and only if $e_{m}^{*}>e_{m}^{* *}\left(e_{m}^{*}=e_{m}^{* *}\right)$. Conversely, the RHS in (40) is always equal or larger than 1 when $V \geq T$. When $V<T$, the RHS in (40) is equal or larger than 1 if an only if $w \leq \underline{w}_{m}$, where:

$$
\underline{w}_{m}=1+\frac{2 e_{m}^{*}}{z}
$$

Given $e_{m}^{*}<e^{*}$ and $3 e_{m}^{*}>2 e^{*}$, by comparing (13) and (41), it can be easily verified that $\underline{w}<\underline{w}_{m}$. 


\section{References}

Arrow, K. (1962). Economic welfare and the allocation of resources for invention. In The rate and direction of inventive activity: Economic and social factors. Universities-National Bureau Committee for Economic Research, Committee on Economic Growth of the Social Science Research Council (pp. 609-626). Princeton University Press, Princeton. ISBN: 0-87014-304-2

Barzel, Y. (1997). Economic Analysis of property rights. Political Economy of Institutions and Decisions. Cambridge: Cambridge University Press.

Baye, M. R., \& Hoppe, H. C. (2003). The strategic equivalence of rent-seeking, innovation, and patentrace games. Games and Economic Behavior, 44(2), 217-226.

Baye, M. R., Kovenock, D., \& De Vries, C. G. (1996). The all-pay auction with complete information. Economic Theory, 8(2), 291-305.

Baye, M. R., Kovenock, D., \& De Vries, C. G. (2012). Contests with rank-order spillovers. Economic Theory, 51(2), 315-350.

Bhagwati, J. N. (1982). Directly unproductive, profit-seeking (DUP) activities. The Journal of Political Economy, 90, 988-1002.

Blavatskyy, P. R. (2010). Contest success function with the possibility of a draw: axiomatization. Journal of Mathematical Economics, 46(2), 267-276.

Buchanan, J. M. (1980). Rent seeking and profit seeking. In J. M. Buchanan, R. D. Tollison, \& G. Tullock (Eds.), Toward a theory of the rent-seeking society (pp. 3-15). College Station, TX: Texas A\&M University Press.

Buchanan, J. M. (1983). Rent seeking, noncompensated transfers, and laws of succession. Journal of Law and Economics, 26(1), 71-85.

Chowdhury, S. M., \& Sheremeta, R. M. (2011a). A generalized Tullock contest. Public Choice, 147(3-4), 413-420.

Chowdhury, S. M., \& Sheremeta, R. M. (2011b). Multiple equilibria in Tullock contests. Economics Letters, 112(2), 216-219.

Chowdhury, S. M., \& Sheremeta, R. M. (2015). Strategically equivalent contests. Theory and Decision, 78(4), 587-601.

Chung, T.-Y. (1996). Rent-seeking contest when the prize increases with aggregate efforts. Public Choice, 87(1-2), 55-66.

Congleton, R. D. (1986). Rent-seeking aspects of political advertising. Public Choice, 49(3), $249-263$.

Congleton, R. D. (1989). Efficient status seeking: Externalities, and the evolution of status games. Journal of Economic Behavior and Organization, 11(2), 175-190.

Congleton, R. D., \& Hillman, A. (2015). A companion to rent seeking: Theory and practice. Cheltenham, UK: Edward Elgar.

Congleton, R. D., Hillman, A. L., \& Konrad, K. A. (2008). 40 years of research on rent seeking: Theory of rent seeking (Vol. 1). Heidelberg: Springer.

Congleton, R. D., Hillman, A. L., \& Konrad, K. A. (2008b). 40 years of research on rent seeking: Rent seeking in practice (Vol. 2). Heidelberg: Springer.

Cowling, K., \& Mueller, D. C. (1978). The social costs of monopoly power. The Economic Journal, 88, $727-748$.

Crain, W. M., \& Ekelund, R. B. (1976). Chadwick and demsetz on competition and regulation. Journal of Law and Economics, 19(1), 149-162.

Dari-Mattiacci, G., Langlais, E., Lovat, B., \& Parisi, F. (2007). Crowding-out in productive and redistributive rent-seeking. Public Choice, 133(1-2), 199-229.

Dasgupta, A., \& Nti, K. O. (1998). Designing an optimal contest. European Journal of Political Economy, 14(4), 587-603.

Dasgupta, P., \& Stiglitz, J. (1980). Uncertainty, industrial structure, and the speed of R\&D. The Bell Journal of Economics, 1980, 1-28.

Dechenaux, E., Kovenock, D., \& Sheremeta, R. M. (2015). A survey of experimental research on contests, all-pay auctions and tournaments. Experimental Economics, 18(4), 609-669.

Dechenaux, E., \& Mancini, M. (2008). Auction-theoretic approach to modeling legal systems: An experimental analysis. Applied Economics Research Bulletin, 2, 142-177.

Demsetz, H. (1973). Industry structure, market rivalry, and public policy. Journal of Law and Economics, 16(1), 1-9. 
Demsetz, H. (1976). Economics as a guide to antitrust regulation. Journal of Law and Economics, 1976, 371-384.

Denicolo, V. (1999). The optimal life of a patent when the timing of innovation is stochastic. International Journal of Industrial Organization, 17(6), 827-846.

Dixit, A., \& Norman, V. (1978). Advertising and welfare. The Bell Journal of Economics, 28, 185-200.

Dixit, A. K. (1987). Strategic behavior in contests. American Economic Review, 77(5), 891-98.

Fung, M. K. (2002). Technological opportunity and economies of scale in research productivity: A study on three global industries. Review of Industrial Organization, 21(4), 419-436.

Gilbert, R. J., \& Katz, M. L. (2011). Efficient division of profits from complementary innovations. International Journal of Industrial Organization, 29(4), 443-454.

Gupta, S., \& Swenson, C. W. (2003). Rent seeking by agents of the firm. Journal of Law and Economics, 46(1), 253-268.

Hartwick, J. M. (1991). Patent races optimal with respect to entry. International Journal of Industrial Organization, 9(2), 197-207.

Hillman, A. L., \& Riley, J. G. (1989). Politically contestable rents and transfers. Economics and Politics, $1(1), 17-39$.

Hillman, A. L., \& Samet, D. (1987). Dissipation of contestable rents by small numbers of contenders. Public Choice, 54(1), 63-82.

Hirshleifer, J. (1971). The private and social value of information and the reward to inventive activity. The American Economic Review, 61(4), 561-574.

Konrad, K. A. (2009). Strategy and Dynamics in Contests. New York, NY: Oxford University Press.

Krishna, V., \& Morgan, J. (1997). An analysis of the war of attrition and the all-pay auction. Journal of Economic Theory, 72(2), 343-362.

Krueger, A. O. (1974). The political economy of the rent-seeking society. The American Economic Review, 64, 291-303.

Lazear, E. P., \& Rosen, S. (1981). Rank-order tournaments as optimum labor contracts. The Journal of Political Economy, 89(5), 841-864.

Lee, S., \& Kang, J. H. (1998). Collective contests with externalities. European Journal of Political Economy, 14(4), 727-738.

Lin, P. (1997). License to be more innovative. Review of Industrial Organization, 12(2), 271-278.

Littlechild, S. C. (1981). Misleading calculations of the social costs of monopoly power. The Economic Journal, 362, 348-363.

Ménière, Y., \& Parlane, S. (2008). Innovation in the shadow of patent litigation. Review of Industrial Organization, 32(2), 95-111.

Moldovanu, B., \& Sela, A. (2001). The optimal allocation of prizes in contests. American Economic Review, 91, 542-558.

Münster, J. (2009). Group contest success functions. Economic Theory, 41(2), 345-357.

Nitzan, S. (1991). Collective rent dissipation. The Economic Journal, 101, 1522-1534.

Nitzan, S. (1994). Modelling rent-seeking contests. European Journal of Political Economy, 10(1), $41-60$.

Nti, K. O. (1997). Comparative statics of contests and rent-seeking games. International Economic Review, 38, 43-59.

Nti, K. O. (1999). Rent-seeking with asymmetric valuations. Public Choice, 98(3-4), 415-430.

Paul, C., \& Wilhite, A. (1994). Illegal markets and the social costs of rent-seeking. Public Choice, $79(1-2), 105-115$.

Rai, B. K., \& Sarin, R. (2009). Generalized contest success functions. Economic Theory, 40(1), 139-149.

Skaperdas, S., \& Grofman, B. (1995). Modeling negative campaigning. American Political Science Review, 89(01), 49-61.

Tullock, G. (1967). The welfare costs of tariffs, monopolies, and theft. Western Economic Journal, 5(3), 224-32.

Tullock, G. (1980). Efficient rent-seeking. In J. M. Buchanan, R. D. Tollison, \& G. Tullock (Eds.), Toward a Theory of the Rent-Seeking Society (pp. 97-112). College Station, TX: Texas A\&M University Press. 